\title{
Cued recall for four-word categories presented in separate pairs
}

\author{
GEORGE A. WEIGEL, JOEL D. SCHENDEL, and HENRY M. HALFF \\ University of Illinois at Urbana-Champaign, Urbana, Illinois 61801
}

\begin{abstract}
Theoretical arguments and empirical evidence are presented that support the view that interitem associations develop among items of the same category during learning of categorized lists. The theoretical arguments question the interpretation of certain cued recall studies that failed to find effects of cues beyond aiding retrieval of the category itself. The empirical evidence is an experiment that shows that cues are more effective at aiding the retrieval of category mates presented adjacent to the cue than of those presented in more remote positions. There was also evidence of withincategory subclusters induced by clustering in the presentation order.
\end{abstract}

What happens when a categorized list of words is memorized? The traditional view is that associations develop between individual items, especially between items of the same category. According to this view, recall depends on the activation of interitem linkages that were developed during storage of the list in memory. Words of the same category tend to be recalled together because associations are likely to have been established or strengthened among them. Theories of memory postulating direct interitem associations probably predate Ebbinghaus, and they still are prominent in our thinking today (e.g., Anderson, 1972, 1976; Anderson \& Bower, 1973; Kintsch, 1970).

An alternative view of the process holds that interitem associations do not develop during list study. Instead, it is suggested that subjects detect the general categorical structure of the list and generate a superordinate control element to represent each perceived subset of items (Matthews \& Tulving, 1973; Roediger, 1973; Rundus, 1973). According to this view, any particular word within a subset is accessed via its associated control element. Words of the same category tend to be recalled together because associations are likely to have been established between them and a common control element.

Research designed to provide support for one of these competing accounts has relied on variations of the partlist retrieval cue technique. This technique typically involves presenting subjects a list of words blocked by categories. Following presentation, varying numbers of list items from each category are presented as cues for

Correspondence should be addressed to Joel D. Schendel, who is now with the U.S.Army Research Institute for the Behavioral and Social Sciences, 5001 Eisenhower Avenue, Alexandria, Virginia 22333. George A. Weigel is now unaffiliated and living in Wilmington, Delaware. Henry M. Halff is now at the Office of Naval Research, Arlington, Virginia. The views expressed in this paper are those of the authors and do not necessarily reflect the views of the United States Army, Navy, or Department of Defense. recall (Roediger, 1973; Rundus, 1973; Slamecka, 1968, 1972) or recognition (Slamecka, 1975) of the remaining words. These investigators reason that, if interitem associations are formed between related words, the proportion of words recalled per category should increase as the number of cues per category increases, for the more cues given, the more likely an otherwise unused association will be aroused. In contrast, if words from the same category are accessed via a common control element, the proportion of words recalled per category should be the same with one cue or with multiple cues. This is because cuing would serve merely to reinstate control elements that might not have been used, and one word from a category would fulfill this purpose as well as multiple cues.

Studies employing the part-list retrieval cue technique have resulted in impressive support for a hierarchical memory structure. Cuing aids recall, but only, it seems, by facilitating access to categories. Cuing does not enhance the retrieval of specific items within a recalled category (Rundus, 1973). But is the evidence strong enough to dismiss the view that interitem associations are formed during list learning? We suggest that it is not, and we offer theory and data to support this contention.

First, providing multiple cues may actually have interfering effects on recall. For one thing, providing an arbitrarily chosen word or set of words as cues may disrupt retrieval strategies that would normally be used and that might be more effective than those the subject invents for the cues. Another problem might arise due to the necessity to edit the cues themselves from the recall protocol. Finally, Rundus (1971) himself suggests that well-worn retrieval methods may be abandoned when they keep retrieving the same items. It is not difficult to see how the presentation of cues would cause even more rapid abandonment of such retrieval paths. (Rundus' argument was presented within the context of a hierarchical, control-element theory, but the principle applies equally well to an associationist theory.)

There is a second reason for questioning the view that 
interitem associations are not formed during list learning. If one considers the nature of an "optimal cue," it appears that relatively few such cues are likely to be provided under the part-list retrieval cue technique. If interitem associations do develop during list learning, the optimal cue to give a subject would be the word that had the richest network of associations with other words in the list. However, because of this rich network of associations, such a word would be one that a subject probably would be able to recall on his own. The act of including it on a cue sheet, therefore, would do little to improve a subject's performance beyond what he probably could do on his own. Conversely, to aid a subject's performance, one would have to cue him with a word that he otherwise would not have recalled. However, it is these unrecallable words that make the poorest cues, since they have relatively few associations to other words on the list.

Allow us to press this last point one step further using a concrete example. In his first experiment, Slamecka (1972) gave zero, one, or four words per category as cues for recall of five-word categories. However, the lowest average proportion of words recalled per category for those subjects given no cues was .62. Thus, on the average, Slamecka's (1972) subjects were able to cue themselves with three words for each category they were able to recall. In his second experiment, Slamecka (1972) gave zero, one, or three words per category as cues for recall of four-word categories. However, the average proportion of words recalled per category for those subjects given no cues was .79. Thus, on the average, these subjects were able to cue themselves with slightly more than three words-more than the maximum number of cues given.

To summarize, it seems likely that the failure to find a recall advantage for multiple cues does not necessarily mean that no interitem associations are formed among items in learning a categorized list of words. On the contrary, interitem associations may be established, but their existence may not be revealed by experiments using the part-list retrieval cue technique. This is because of the possibility that multiple cues have an interfering effect as well as a facilitating effect on recall and because it is likely that relatively few effective cues are provided, even under multiple-cue conditions.

The purpose of this research was to pose a more sensitive test for the possibility that, in learning a categorized list, interitem associations develop among items within a category. Using particular presentation orders, we created a situation in which interitem associations would be likely to develop among some items of a category, but not among all items. This was accomplished by presenting each of 18 four-word categories in two pairs separated in the list by at least six pairs of words from other categories. Some theorists (Glanzer, 1969; Kintsch, 1970) have suggested that when related items are together in short-term memory, the organization of these items is accomplished. If this organization is in the form of interitem associations, words within pairs would have associations established between them, whereas associations would not be established between pairs of a given category. Whether such associations in fact develop was tested by giving subjects one word from a category as a cue and asking them: (1) to recall in any order the three other words in the cue word's category, and (2) to give a reasonable category name for the cue word and any words he might recall.

If interitem associations develop during storage, the word that had been presented next to the cue should be recalled more frequently than either of the other two words of its category. This should be the case even when a subject gives a category name that includes all four instances of the experimenter-defined category. The word next to the cue is more likely to be linked associatively to the cue than is either of the two words from the other pair, and it is more likely enhanced by the cue. In contrast, if interitem associations do not develop during list memorization, recall frequency of words within a category should be equal. This would be true because cuing in this instance would serve merely to reinstate the category name. If a subject is searching within an appropriate category, and if all words of a category have similar strengths in memory, all instances of a category should be equally likely to be recalled, irrespective of their positions relative to the cue during presentation.

\section{METHOD}

Stimuli

A pool of 72 English nouns was obtained by selecting four words from each of 18 categories in the Battig and Montague (1969) category norms. The average taxonomic frequency of the items selected was approximately equal for all of the categories, and the interitem association value was very low for items within each category (Marshall \& Cofer, 1970).

The words in each list were arranged so that two items from each category were presented adjacently, pairs of words from other categories appearing before the presentation of the second pair of the category. Six categories were randomly chosen to be buffer categories. The first pair of each of these categories was placed in the beginning of each list, and the second pair was placed at the end of the list. The remaining 12 categories were arranged in the middle of the list, where the probability of recall would be approximately equal for all serial positions.

Pairs were formed by selecting the most frequent instance of a category to be the cue word $(C)$. The second most frequent instance $\left(\mathrm{T}_{2}\right)$ was chosen to be the first word of the pair not including $C$. The two least frequent items $\left(T_{1}\right.$ and $\left.T_{3}\right)$ were selected as the second member of each pair.

\section{Design}

Four lists were created by crossing two levels of cue assignment (first or second pair) with two levels of item assignment $\left(T_{1}\right.$ or $\left.T_{3}\right)$. The first variable was included as a further control for serial position effects; the second was included as a control for the association between $C$ and the second word of its pair. Both variables were manipulated between subjects. Within each list, 3 of the 12 target categories were arranged $C-T_{1}: T_{2}-T_{3}$; 3 were arranged $T_{2}-T_{3}: C-T_{1} ; 3$ were arranged $C-T_{3}: T_{2}-T_{1}$; and 3 were arranged $T_{2}-T_{1}: C-T_{3}$.

The number of pairs $(6,8$, or 10$)$ intervening between pairs from the same category was a within-subjects variable. One category for each arrangement of $\mathrm{C}$ and $\mathrm{T}_{2}$ had one of the three spacing values. The spacing variable was included merely in an 
attempt to prevent subjects from detecting the structure of the list and, hence, anticipating the occurrence of the second pair of a category.

\section{Subjects}

The subjects were 42 introductory psychology students from the University of Illinois who volunteered to participate in the experiment to fulfill a course requirement. The subjects were tested in groups of from two to four. Ten subjects saw one of the lists, 10 saw a second, 11 saw the third list, and 11 saw the fourth.

\section{Procedure}

Each subject was seated at a separate booth, and instructions were read regarding the presentation of the list. The subjects were told: (1) the list length, (2) that the list was categorized and that this might aid them in learning the list, and (3) the rate of presentation. The subjects also were given a four-instance example of what was meant by a category.

The subjects were instructed to try to remember as many words as possible but were not told: (1) the exact nature of testing, (2) the number of categories, (3) the number of words per category, or (4) that the instances of a category were presented in two pairs spaced in the list. The list was then presented on slides at a 1.5 -sec rate $(.5 \mathrm{sec}$ exposure per slide with $1.0 \mathrm{sec}$ for slide change).

After presentation, instructions were read for cued recall. The subjects were given a booklet with 18 sheets, one $\mathrm{C}$ word printed on each sheet in a random order. The subjects were then told to write on each sheet, in any order, the three other words from the list that could be members of the same category as the cue word. In addition, subjects were told to write a category name for the cue word and the words they were able to recall. The example given in the instructions for presentation was given again to clarify these tasks. The subjects were paced through the booklet at a rate of $30 \mathrm{sec} / \mathrm{sheet}$. Twenty seconds were allowed for written recall, after which $10 \mathrm{sec}$ were allowed to write a category name. The subjects were required not to begin work on a sheet until they were instructed and never to turn back to any earlier sheets.

\section{RESULTS}

Only the 12 target categories were considered for analysis. Table 1 presents recall frequencies of item types for cases in which only one word was recalled correctly. For all lists combined, the word next to the C word was recalled more frequently than either of the words from the other pair; this held true regardless of whether the subject gave a category name that included each of the four instances in the list. A chi-square test comparing the distribution of item types for cases in which subjects gave a category name that included each

Table 1

Recall Frequencies of Item Types for Cases in Which Only One Word Was Recalled Correctly

\begin{tabular}{|c|c|c|c|c|c|c|c|c|}
\hline \multirow{4}{*}{$\begin{array}{l}\text { Lists } \\
1 \& 3 \\
2 \& 4\end{array}$} & \multicolumn{6}{|c|}{ Item Type } & \multirow{2}{*}{\multicolumn{2}{|c|}{ Total }} \\
\hline & \multicolumn{2}{|c|}{ Next to $\mathrm{C}$} & \multicolumn{2}{|c|}{$\mathrm{T}_{2}$} & \multicolumn{2}{|c|}{$\mathrm{T}_{2}$ 's Pairmate } & & \\
\hline & 45 & (42) & 22 & (20) & 21 & (19) & 88 & ( 81) \\
\hline & 53 & (46) & 25 & (20) & 26 & (26) & 104 & (92) \\
\hline Total & 98 & (88) & 47 & (40) & 47 & (45) & 192 & (173) \\
\hline
\end{tabular}

Note-The values outside the parentheses are for all cases. The values inside the parentheses are cases in which a category name that included all items was given.
Table 2

Recall Frequencies of Item Types for Cases in Which Two Words Were Recalled Correctly

\begin{tabular}{ccccccccc}
\hline & \multicolumn{6}{c}{ Item Type } \\
\cline { 2 - 8 } Lists & \multicolumn{1}{c}{ Next to C } & \multicolumn{2}{c}{$T_{2}$} & \multicolumn{2}{c}{$T_{2}$ 's Pairmate } & \multicolumn{2}{c}{ Total } \\
\hline 1 \& 3 & 20 & $(19)$ & 26 & $(23)$ & 26 & $(24)$ & 72 & $(66)$ \\
$2 \& 4$ & 18 & $(17)$ & 34 & $(33)$ & 30 & $(30)$ & 82 & $(80)$ \\
Total & 38 & $(36$, & 60 & $(56)$ & 56 & $(54)$ & 154 & $(146)$ \\
\hline
\end{tabular}

Note-The values outside the parentheses are for all cases. The values inside the parentheses are cases in which a category name that included all items was given.

of the four instances in the list proved to be highly significant $(p<.001)$. Furthermore, an examination of the results obtained under Lists 1 and 3 vs. Lists 2 and 4 demonstrates that this effect cannot be attributed to a particular arrangement of $\mathrm{C}$ and $\mathrm{T}_{1}$ or $\mathrm{T}_{3}$ during presentation.

Table 2 presents the distribution of item types when two words were recalled correctly. Unexpectedly, a strong tendency can be observed for the word next to $\mathrm{C}$ to be recalled less often than either of the words in the other pair. This effect is especially visible under conditions in which $T_{2}$ was the first word recalled. Of a total of 30 instances in which $T_{2}$ was the first word recalled, there were 22 instances in which the second word recalled was the word next to $T_{2}$ and only 8 instances in which the second word recalled was the word next to $\mathrm{C}$.

For cases in which all three words of a category were recalled, the probability that the word next to $C$ was the first word recalled was approximately equal to the probability that either of the words in the other pair was the first recalled. Of a total of nine instances in which all three words of a category were recalled correctly, there were four instances in which the word next to $C$ was recalled first, two instances in which $T_{2}$ was recalled first, and three instances in which the word paired with $T_{2}$ was recalled first.

\section{DISCUSSION}

To summarize the results, when one word was recalled, it tended to be the word that had been next to the cue during presentation. However, when two words were recalled, they tended to be the two words of the other pair. The first result is clearly consistent with the view that interitem associations develop during categorized list learning, but the second is more puzzling. (At this point, we replicated the experiment using a separate sample of 24 subjects. We obtained essentially the same results.)

The pattern of results in these experiments can best be understood within a theory that allows both interitem associations and more global retrieval processes. These components can be incorporated in the following simple model of the experiment. Assume that members of a category presented in adjacent positions develop an interitem association with probability a, but that such associations are virtually nonexistent between items separated in the presentation order. To account for more global organization, assume that items in the same category develop a category association with probability c, and that this event is independent of presentation order and any other associations formed. 
Table 3

Joint Frequency Distribution of Recall of Items Presented Adjacent to and Remote from $\mathrm{C}$

\begin{tabular}{cccr}
\hline & \multicolumn{3}{c}{ Remote } \\
\cline { 2 - 4 } Adjacent & $\mathrm{R}_{0}$ & $\mathrm{R}_{1}$ & $\mathrm{R}_{2}$ \\
\hline $\mathrm{A}_{0}$ & 223 & 97 & 39 \\
$\mathrm{~A}_{1}$ & 98 & 38 & 9 \\
\hline
\end{tabular}

Note $-R_{0}, R_{1}$, and $R_{2}$ represent recall of zero, one, and two remote items, respectively. $A_{0}$ and $A_{1}$ are defined correspondingly for adjacent items.

Now at recall assume that subjects will have no trouble using the cue to find categories that will support recall via category associations and, of course, that interitem associations will also support recall. Hence items presented adjacent to the cue will be recalled if either an interitem or a category association is formed for those items.

Remote items $\left(T_{2}\right.$ or its pairmate $\left.T_{3}\right)$ will be recalled with a category association. $T_{2}$, for example, could be recalled with a category association and then itself cue its pairmate via an interitem association. It is this dual-path assumption that explains why remote words were recalled so often when only two words were recalled (see Table 2).

This model makes two specific predictions about the data presented in Table 3 (which was derived from Tables 1 and 2 and other data presented above). Table 3 shows the joint frequencies of the event, $A_{0}$, no recall of the item adjacent to the cue, and its complement, $A_{1}$, together with events termed $R_{0}$, $R_{1}$, and $R_{2}$, respectively, representing recall of zero, one, or two of the remote category items. The first prediction of the model is that row and column events in Table 3 should be mutually independent, since interitem associations between separated pairs are impossible. This prediction is not contradicted by the present data $\left[x^{2}(2)=2.86\right]$.

The second prediction that can be derived from the model concerns the relationships between the marginal frequencies of Table 3. It follows from the process assumptions presented above that

$$
\begin{aligned}
& P\left(A_{0}\right)=(1-c)(1-a), \\
& P\left(R_{0}\right)=(1-c)^{2}, \text { and } \\
& P\left(R_{1}\right)=2 c(1-c)(1-a) .
\end{aligned}
$$

Here we have three equations in two unknowns (a and c) and hence a prediction concerning the quantities on the left-hand side of Equation 1. The best-fitting values of $a$ and $c$ are .134 and .200 , respectively, using minimum chi square as a criterion. The value of chi square obtained using these values is not significant $\left[\chi^{2}(4)=5.21\right]$. Note from Table 3 that the relative frequencies of $A_{0}, R_{0}$, and $R_{1}$ are $.712, .637$, and .268 , respectively. These may be compared with the predictions by using the above estimates of a and $\mathrm{c}$ in Equation 1; the corresponding predicted values are $.693, .640$, and .277 .

One final point about the model concerns the main issue of this paper. The parameter $c$ represents global recall paths and, in fact, the only recall paths from the cue to $T_{2}$ and $T_{3}$. As we have pointed out, there is much evidence to indicate that something like a category name is involved in these paths. Our intention was to determine if the parameter a, representing particular interitem associations, could possibly be 0 . When the model is evaluated under the restriction that $a=0$, we find that chi square can be brought no lower than a highly significant 36.77 (df $=5$, $\mathrm{p}<.001)$.

Theory and data suggest that current accounts of categorized list learning are inadequate, failing to recognize the development of interitem associations during list study. The theoretical account proposed here characterizes the learning of categorized material as consisting of a directed search via control elements for associatively related items. While intended only as a first approximation, this account seems to provide a reasonable way of meeting the questions raised during the course of this paper.

\section{REFERENCES}

Anderson, J. R. FRAN: A simulation model of free recall. In G. H. Bower (Ed.), The psychology of learning and motivation (Vol. 5). New York: Academic Press, 1972.

Anderson, J. R. Language, memory and thought. Hillsdale, N.J: Erlbaum, 1976.

Anderson, J. R., \& Bower, G. H. Human associative memory. New York: Wiley, 1973.

Battig, W. F., \& Montague, W. E. Category norms for verbal items in 56 categories: A replication and extension of the Connecticut category norms. Journal of Experimental Psychology Monograph, 1969, 80, 1-46.

GLANZER, M. Distance between related words in free recall: Trace of the STS. Journal of Verbal Learning and Verbal Behavior, $1969,8,105-111$.

KintSCH, W. Models for free recall and recognition. In D. A. Norman (Ed.), Models of human memory. New York: Academic Press, 1970.

Marshall, G. R., \& Cofer, C. N. Single word free association norms for 328 responses from the Connecticut cultural norms for verbal items in categories. In L. Postman \& G. Keppel (Eds.), Norms of word association. New York: Academic Press, 1970.

Mathews, R. C., \& Tulving, E. Effects of three types of repetition on cued and noncued recall of words. Journal of Verbal Learning and Verbal Behavior, 1973, 12, 707-721.

RoEdiger, H. L. III. Inhibition in recall from cueing with recall targets. Journal of Verbal Learning and Verbal Behavior, 1973, 12, 644-657.

RuNDUs, D. Analysis of rehearsal processes in free recall. Journal of Experimental Psychology, 1971, 89, 63-77.

Rundus, D. Negative effects of using list items as recall cues. Journal of Verbal Learning and Verbal Behavior, 1973, 12, 43-50.

Slamecka, N. J. An examination of trace storage in free recall. Journal of Experimental Psychology, 1968, 76, 504-513.

Slamecka, N. J. The question of associative growth in the learning of categorized material. Journal of Verbal Learning and Verbal Behavior, 1972, 11, 324-332.

SlameckA, N. J. Intralist cueing of recognition. Journal of Verbal Learning and Verbal Behavior, 1975, 14, 630-637.

(Received for publication February 12, 1980.) 